Papers $48,1996 \quad 147 \cdot 150$

\title{
Obituari
}

\section{Lluís Carreño i Piera: memòria personal}

\author{
Salvador Giner
}

EI $S$ de febrer d'enguany morí Lluís Carreño, que fou president i un dels fundadors de l'Associació Catalana de Sociologia. Fou també un dels introductors principals de la professió al nostre país. Per raons d'estreta amistat amb ell, i per haver compartit una part important dels seus esforços com a sociòleg, les ratlles que dedico aquí a la seva memòtia tindran forçosament un tarannà de record personal. De segur que altres podrien donar una visió més arrodonida de la rica personalitat d'en Lluís Carreño, com també de la seva faceta com a home públic i com a ciutadà molt actiu, la presència del qual ha estat força important en la vida recent del país, i sobretot de la ciutar de Barcelona.

En Lluís Carreño i Piera nasqué a Barcelona l'any 1933, en el si d'un família culta i professional. El seu pare, metge, coneixia la meva família, i abans que tots dos entréssim alhora a la Universitat jo ja havia estat a la casa, burgesament ben endreçada, on els Carreño vivien, a la dreta de l'Eixample, al costat de mar de la Diagonal. L'abundància de llibres d'aquella casa restava eclipsada per l'exotisme de les vitrines plenes de vanos i altres objectes, molts d'ells orientals, duts per l'avi des de les Filipines. Potser tot això ajudà a donar a Iluís Carreño l'aire un xic aristocràtic que sempre tingué - de jovenet ja semblava un gentleman - i la seva atracció per l'estranger, per Europa. Aquests trets aviat el distingiren dels altres estudiants quan entrà a la Universitat, per estudiar-hi dret. El seu interès pels estudis de la cosa jurídica era, però, i com el de tants d'altres que hi érem, més aviat circumstancial. Esperava fer alguna altra cosa a la vida, com em digué amb un posat un xic misteriós un dels primers dies de classe, que celebràrem passejant pel jardí acadèmic en comptes d'assistint a la lliçó de Formación del Espiritu Nacional. Aquesta darrera assignatura pretenia en va transformar els alumnes en aspirants a bons feixistes.

La nostra amistat es desenvolupà al voltant de les aules de la Facultat per raons verament extrapolítiques. Malgrat que tots dos militàvem en moviments clandestins contra la dictadura, el que ens uní fou un desencís fort amb una carrera que no sentiem nostra i la recerca compartida d'una sortida intel.lecttıal diversa. Com he tingut ocasió de dir en alguna oportunitat, Lluís Carreño fou la primera persona amb la qual vaig poder «enraonar» de sociologia. De fet, la 
descobrírem plegats. Exploràvem les llibreries de vell del carrer d'Aribau i compràvem edicions anteriors a la guerra civil d'autors clàssics de l'economia, la política i la sociologia, algunes d'importades de l'Argentina o Mèxic, que per la seva aparent inanitat burlaven l'arbitrària mà dels poc diligents censors de duana. De tots els textos que queien a les nostres mans, els que parlaven de quelcom remot que s'anomenava "sociologia" eren els que més ens atreien.

En Lluís Carreño desenvolupà aviat un interès paral.'el per altres activitats, com ara la possibilitat d'entrar en el cos diplomàtic, el qual, al meu parer, escindí un xic la seva vocació primera. Fou així com es llicencià en Ciències Polítiques a la Universitat de Madrid, on hi féu després els cursos de doctorat corresponents, $i$ acabà els estudis de Dret a Barcelona. El seu interès per la sociologia no minvava, però. Jo, per la meva part, havia passat el curs de 1957-1958 a la Universitat de Colònia. (En Lluís i jo, i el nostre amic Carlos Moya, un altre futur sociòleg, llavors a Madrid, haviem decidit que l'alemany era cabdal per fer sociologia seriosament!). En tornar els vaig convèncer a tots dos que Colònia era el lloc on calia anar. No crec que anés errat, tot i que em penso molt que algús ha lamentat després de no haver anat a Frankfurt, amb la seva escola marxistitzant, en aquells anys. El cas és que el professor René König, que havia esdevingut allà el meu primer mestre sociològic, ho fou, poc després, el de Lluís Carreño, seguit al final per Carlos Moya. Fou König qui dirigí les meves passes vers qui seria el meu veritable mestre, Enrique Gómez Arboleya. En aquest cas, però, no vaig aconseguir que en Lluís estudiés sota el seu consell.

En tornar de Colònia, el 1961 en Lluis Carreño s'endinsà en una forta activitat organitzativa i de recerca en el camp territorial i de la sociologia urbana, de la qual és testimoni un bon conjunt d'estudis i d'informes que iniciaren, en aquest país, la codificació de les dades urbanístiques, els estudis socioeconòmics territorials i els primers lligams formals entre arquitectes, planificadors i sociòlegs. Amb en Jaume Nualart i jo mateix, participàrem en jornades i seminaris (alguns pràcticament clandestins) organitzats pel Grup R, inspirat, entre altres, per l'Oriol Bohigas, el qual intentà d'establir aquests lligams i de promoure una visió democràtica i multidisciplinària de l'urbanisme i de l'arquitectura.

Mentrestant, en Llús Carreño participava en una curiosa activitat d'apostolat socioldgic entre la societat civil. Sembla que hi ha un cert acord en el fet que l'única càtedra existent aleshores a Catalunya (els primers anys seixanta) no va complir aquesta tasca: no solament hom no la pot comparar ni de bon tros amb la feina intel.lectual que aconseguia desenvolupar en un terreny afí a la mateixa Facultat d'Economia en Manuel Sacristán, sinó que més aviat la sociologia procedent del lloc era percebuda com un element afí a la ideologia oficial, i no com l'eina crítica i fins i tot alliberadora que hom esperava de la disciplina. A tall d'il-Iustració de l'ambient que s'hi respirava, recordem que la Revista Española de Sociologia, de la qual eixiren només el número 0 i l'1, fou tancada per l'autoritat governativa, com a publicació subversiva. Aquesta revista tingué entre els seus fundadors i inspiradors en Lluís Carreño. Editada a Madrid i Barcelona, hi figuràvem a la redacció catalana ell mateix; un "con- 
vers" posterior a nosaltres, però força més gran, l'Esteban Pinilia de las Hcras, i jo mateix.

Durant el decenni dels anys seixanta en Llú́s Carteño s'endinsà cada cop més en les activitats professionals de la sociologia urbana i regional, sovint entrant en conflicte amb la visió oficial, autoritària i centralista dels afers públics. En tornar dels meus estudis a Chicago, el 1964 me'l vaig trobar en un centre privat d'estudis, CEDEC, acabant la direcció d'un estudi sobre l'estat de l'ensenyament a Barcelona. (CEDEC era un cau subversiu on s'editava la revista Promosi on es feien cursos i seminaris sociològics, coordinats per l'Àngels Pascual, que feia també d'alumna). Poc després participà en els cursos extraoficials de ciències socials, però certament molt ben atesos per un alumnat força distingit, que foren organitzats per Antoni Jutglar i jo mateix a la Residència de Sant Anton (afectuosament anomenada Can Colapi), sota els auspicis, si no recordo malament, de la mateixa iniciativa cívica que endegà després una protouniversitat alternativa, EISA, la qual també comptava amb ell en el seu equip. EISA fou tancada amb l'estat d'excepció del 1969; i en Lluís Carreño es feu càrrec, abans de l'esdeveniment, de molts contactes formals amb l'escola paral.lela de Madrid, CEISA, que ja funcionava; ho féu principalment a través d'en Josep Vidal Beneyto.

Aquella fou una època, a més, en què Lluís Carreño consolidà la seva professionalitat amb estades acadèmiques a França i Alemanya. Llavors cs vinculà també al Gabinet Tècnic del Departament de Programació de l'Ajuntament de Barcelona, i començà a dur a terme tot un seguit d'estudis de planejament d'activitat municipal i també d'informes sociològics i demogràfics per a l'alcaldia. Esdevingué assessor de cooperació tècnica de la Corporació Metropolitana de Barcelona, des d'on impulsà i organitzà un nombre considerable de congressos i d'activitats, algunes de mena sociològica, altres més interdisciplinàries, i moltes d'internacionals. Al marge de la seva entrada postcrior al Consorci d'Informació i Documentació de Caralunya, aquestes acrivitats havien de configurar la dimensió pública i ciutadana d’en Lluís Carreño.

Durant els anys seranta en Lluís decidi de romandre fora del món acadèmic i practicar la sociologia com a professió liture de tota docència. (Tanmareix, durant els anys 1962-1966 s'encarregà del curs de sociologia urbana -nom oficial: "Sociologia i Habitatge" - a l'Escola d'Arquitectura.) És curiós que, malgrat la seva intensa activitat per engegar l'Associació Catalana de Sociologia, que ell ajudà a fundar amb uns quants companys, se sorprengués molt i molt quan els seus col.legues de junta el triàrem com a president, l'any 1981. Ja havia refusat el càrec abans amb el pretext que es "trobava fora de la Universitat». L'argument que esgrimíem alguns membres de la junta (entre altres, el secretari d'aleshores, en Jordi Estivill i Pascual) era que en Lluís Carteño podia esdevenir un president ideal precisament perquè no pertanyia a l'academia i era el viu exemple del sociòleg professional, competent $i$ exemplar que calia fomentar. Ell era aleshores secretari executiu del Consorci d'Informació i Documentació de Catalunya. Des d'allà i poques hores després del frustrat cop d'estat que sofrí la democràcia espanyola al febrer de 1981, em va escriu- 
re una esplèndida carta (jo era en aquells moments professor convidat a la Universitat de Yale) insistint en la importància de la nostra Associació com a entitat defensora dels drets cívics dels catalans, $\mathrm{i}$ insistint, però, en el seu refús. Els esdeveniments es precipitaren. La signatura d'un membre forà de la Junta en la redacció del Manifiesto que es publicà llavors contra la llengua catalana (membre que fou invitat a abandonar-la) i les tensions polítiques que hom respirava en el moment posterior al cop el feren acceptar finalment: calia, més que mai, donar suport a l'Institut d'Estudis Catałans, institució a la qual pertanyia i pertany l'Associació. Fou president de l'ACS de 1981 a 1984.

Lluís Carreño fou capdavanter en la presència dels sociòlegs en el si d'altres grups $\mathrm{i}$ associacions professionals. Ell en «normalitzà» la participació, per dirho d'alguna manera. Ja havia estat promotor de la Comunitat de Veïns Esquerra de l'Eixample, en el moment en què les associacions cíviques veïnals adquirien una gran rellevància. Fou membre del Cercle d'Economia, del Comitè del Urban Data Management Symposia, president de la International Association for Regional and Urban Statistics (1978-1979), vicepresident de l'Associació Espanyola de Ciència Regional, membre de la Societat Catalana d'Ordenació del Territori, i de diverses entitats internacionals més. Compatibilitzà tot això amb el càrrec de director de relacions institucionals al Port Autònom de Barcelona (1987-1990), l'assessorament per a la projecció internacional de la capital catalana a la Corporació Metropolitana de Barcelona. Tingué un paper molt destacat en l'anomenat C-6, la Xarxa de Ciutats Espanyoles i Franceses, i coordinà i presidi, recentment, un important congrés internacional de ciència regional.

Lluís Carreño fou un element integrador dins la comunitat cientificosocial catalana. Els seus estrets contactes amb economistes (fou sempre molt amic d'en Jacint Ros Hombravella) i els ja esmentats amb els arquitectes, es complementaren amb esforços decisius per apropar les diverses disciplines i planejar activitats conjuntes. El professor Claudi Esteva Fabregat, per exemple, que acabava de tornar del seu exili mexicà, trobà en Lluís Carreño una immediata porra d'accés a la ciència social espanyola. I, a més, es preocupà exemplarment per la vida i les necessitats dels seus collegues, sobretor les d'aquells que feien una vida, diguem-ne, acadèmicament heterodoxa. El cas més significatiu fou potser el del seu suport i ajut a l'Esteban Pinilla de las Heras, que l'ha precedit d'un any en la seva desaparició. Tant en Jordi Porta, director de la Fundació Jaume Bofill, com jo mateix, podem testificar la paciència, dedicació i companyia que en Lluís Carteño donà amb desinterès i generositat a aquest col.lega nostre que es trobà solitari, gairebé indigent i certament desemparat durant els darrers anys de la seva vida. Només vull dir que fou ell qui trobà les solucions, no gens facils, perquè fos acollit en institucions, com ara les Llars Mundet, on en Pinilia fou tractat com calia, i també a les clíniques i els hospitals on fou ingressat. És aquest el record que vull que més m’acompanyi de la seva vida.

Voldria aprofitar l'avinentesa d'aquestes notes escrites en homenatge a en Lluís Carreño per transmetre el condol dels sociòlegs catalans a la seva vídua, Elena Giráldez, professora de política econòmica a la Universitat, com també a la seva filla. 